\title{
Cause Analysis and Countermeasures of the Absence of Aesthetic Education
}

\author{
Junli Wang \\ Weinan Normal University, Shaanxi, Weinan, 714000, China
}

Keywords: Aesthetic Education; Absence Reason; Problem Analysis

\begin{abstract}
Aesthetic education refers to the arts as the main means of education, combined with natural beauty and the beauty of society, so that educational objects perceive the United States, enjoy the United States and create the United States. The main goal of cultivating talents in higher education in our country is to cultivate students' spiritual independence, freedom of thought and development of their creative thinking so that they respect life and love life, pursue truth, goodness and beauty in study, life and social practice, and ultimately achieve social harmony. Thus, as a perceptual education, aesthetic education is an important complement to rational knowledge education and an important means to perfect the personality of students. For college students, aesthetic education possesses instrumental value. For college students to become a national citizen after entering society, aesthetic education is a manifestation of the ultimate value of life noumenon. Therefore, aesthetic education plays an irreplaceable role in quality education at colleges and universities. However, the aesthetic education in our country is still relatively backward. In fact, the lack of aesthetic education in higher education is very prominent, mainly in the areas of superficial aesthetic awareness, secularization of aesthetic education and entertainment of aesthetic mode. The article analyzes the current situation of aesthetic education the reasons for the absence, and propose specific solutions.
\end{abstract}

\section{Introduction}

The concept of aesthetic education includes two aspects, narrow and broad. Aesthetic education in a narrow sense means aesthetic education through artistic means. Aesthetic education in a broad sense exerts a subtle influence on the object of education by applying all forms of beauty. It cultivates its soul and beautifies its soul, Improve their personality. Although academia does not form a unified and fixed concept of aesthetic education, as an important branch of quality education, it shows remarkable comprehensiveness, transcendence and practicality as well as other forms of education that cannot be replaced.

\section{The Performance of Lacking of Aesthetic Education in Colleges and Universities}

Specifically, the lack of aesthetic education in colleges and universities in our country is mainly reflected in the following aspects:

Since the reform and opening up, the material civilization of our country has made considerable progress. However, the building of spiritual civilization has lagged behind. All kinds of ideological and ideological ideas have hit people's lives, making people's mentality extremely impetuous. Undergraduates have not entered society, their ideas are simple, lack of experience, and easy to accept new things, so bad ideas will have a direct impact on them. The development of various types of new media, variety shows another way to pass the impulsive message to the students. Network knowledge gradually flooded traditional culture, popular music replaced classical music, it is this superficial aesthetic consciousness distorted the students' aesthetic. Under the impact of multiculturalism, pop culture has gradually dissolved the traditional culture's authoritative status in aesthetic education. Popular and superficial forms of art flourished. Under such a cultural background, students The lack of discrimination will lead to the chaos of its values, the world's spiritual world, utilitarian, which directly affects the formation of social responsibility. Aesthetic activities and entertainment itself has a coherent thread, such as edutainment of educational 
philosophy is its best proof. And then, as a kind of perceptual education, it is very difficult for aesthetic education to determine a proper balance between sensibility and rationality. The influence of mass media environment on students is very important. However, the amusement of mass culture can only give people a brief pleasure. Students, In the pursuit of aesthetic perceptual stimulation is too one-sided, this entertaining aesthetic will only make students grow into hedonists, materialists.

\section{The Reasons for the Lack of Aesthetic Education}

Specifically, the main reasons leading to the lack of aesthetic education in colleges and universities include the following aspects:

Beauty is an eternal theme in the process of the development of human civilization. People naturally have the pursuit of beauty and appreciation of beauty. And regardless of gender, occupation and ethnicity, they form a unique and self-understanding and understanding of the United States. However, human social attributes determining the social environment will have an important influence on the way of thinking and life style. Therefore, it is inevitable to form different aesthetic orientations among different people. For example, some people pursue alternative beauty while others appreciate traditional beauty. For undergraduates who are inexperienced, their life is full of possibilities, so their pursuit of beauty is more intense. However, the current social environment surging in all kinds of thoughts cannot give correct and positive guidance to students, making students lack the correct analysis and cognition of the United States, leading to its weak aesthetic awareness and poor aesthetic ability.

The ideological and political education in colleges and universities in our country generally pay more attention to the moral education of students, enlightenment and guidance of students in life, while ignoring the aesthetic education that should keep pace with moral education. In fact, in terms of Marxist ideological education, Marx's aesthetic education thought is also very rich and incisive. Marx not only put forward a completely new concept of education, but also put forward a completely new concept of art. Therefore, aesthetic education in universities is indispensable. However, utilitarian and pragmatic education concept leads to the lack of aesthetic education in ideological and political education. At this stage most of the college students are 95, the pursuit of freedom, enthusiasm, the traditional mode of preaching has serious political tendencies, simply cannot meet their psychological needs, and even lead to its adverse emotions, in which case cannot Effectively guide students to actively, take the initiative to accept aesthetic education, its aesthetic ability to enhance also talk about it.

Aesthetic subjects are individuals. Although beauty is ubiquitous and ubiquitous in every corner of the world, students are influenced by their own literacy, life experiences, interpersonal relationships and family environment, and their aesthetic abilities also exist Big differences, students lack of self-cultivation is likely to confuse the concept of beauty and ugliness, cannot find beauty, experience beauty. Personal accomplishment is accumulated through long-term practice of social life, which is not only reflected in the students' thinking but also in their ability and quality. Most of the students are in school. The campus is an important place for them to contact with new things and form their perceptual cognition. Its social experience is shallow and cultural attainment has not reached a certain height, so it cannot form knowledge when it accepts aesthetic education Internalization, and ultimately affect the improvement of its aesthetic ability.

\section{The Strategy to Improve the Effectiveness of College Aesthetic Education}

Aesthetic education in colleges and universities for the lack of status quo, it is recommended to start from the following aspects in order to improve the effectiveness of aesthetic education:

As mentioned above, aesthetic education in narrow sense means aesthetic education through artistic means. Thus, art education is the core content of aesthetic education and also the main way. Compared with other education methods, art education is the most concentrated, most direct and typical aesthetic activity, which is the formal representation of natural beauty and social beauty. In actual art education, teachers should consciously desalinate the education of artistic knowledge, 
focusing on the education of universal aesthetic appreciation and artistic experience, such as art appreciation and art practice activities, and set up films, plays, poems, music, paintings, etc. A variety of art appreciation courses to enrich their artistic knowledge and enhance their aesthetic level. In addition, it is necessary to create an aesthetic education document on campus to guide college students to take the initiative to participate in the aesthetic through various means such as student associations and social practice activities, to actively explore and master the knowledge of applied arts to enrich the teaching of subjects and to excavate students through artistic channels The artistic potential, and ultimately enhance their aesthetic ability and personality accomplishment.

From the perspective of aesthetic education, the individual's perception of aesthetics and its mode of production will have a decisive influence on the way of life and behavior. The ultimate goal of aesthetic education is to make the students' aesthetic point of view and aesthetic taste become part of their psychological temperament, and have an impact on their code of conduct, thus enhancing their aesthetic accomplishment. The emotional characteristics of incorporating beauty into ideological and political education can weaken the dogmatic and theoritical deficiencies in ideological and political education and stimulate students' enthusiasm for learning. For example, learning the just-concluded 19 major spiritual activities, teachers use dogmatic preaching recitation way will make students feel boring learning, and into the aesthetic education can enrich the teaching content and teaching methods. For example, when learning the relevant contents of the eco-environment, you can apply the contrast picture of the multimedia courseware display environment to display the related videos of nature and life, and under the condition that the students are allowed to observe the art exhibition and so on to guide the students to appreciate The external association thinks of the meaning it implies to make it enjoy emotional pleasure, deepen its cognition and sublimate its emotion.

Mentioned above, aesthetic education is an important content of China's higher education, but also one of China's education policy, so in all aspects of education must run through the aesthetic education, in various disciplines, into the aesthetic education content, as a whole to create a beautiful state of education. The university education system should be combined with the students' life experience and knowledge structure. Throughout its professional study, aesthetic education should be carried out in and out of class. Colleges and universities should change the traditional concept of education and optimize the design of aesthetic education curriculums so that the aesthetic education develops in a systematic and long-term direction. In order to avoid the utilitarianization of aesthetic education, aesthetic education should not apply the traditional evaluation methods to evaluate its educational effects. Instead, the direction of education should be to improve the aesthetic taste of students, and to enhance students' imagination through the infection and influence of aesthetic education, Appreciation and creativity, and influence its form and behavior from the outside, cultivating its noble sentiments from the inside. And should continue to expand the scope of aesthetic education, expand the visual field of aesthetic education, aesthetic education will be extended to school, in the social activities of students arranged aesthetic teaching content. In addition, the Internet and other mass media platforms, such as the media, are being depraved to make use of the Internet resources to enrich and refine the contents and methods of aesthetic education in schools so that students can embrace the beauty and enhance their comprehensive qualities in all directions and angles.

\section{Conclusion}

In short, aesthetic education is an indispensable part of college personnel training and an important way to improve the overall quality of students. The majority of educators should fully realize that aesthetic education is not only an educational method but also an education philosophy, this concept must be infiltrated in the daily teaching activities, throughout the college students in the entire learning process. Admittedly, the problem of the lack of aesthetic education in our country is still outstanding. Compared with the cultural and educational powerful country, the aesthetic education in our country lags behind. However, with the continuous promotion of quality education in higher education and the constant reform of personnel training strategy, aesthetic education will 
occupy an increasingly important position in the quality education system. As long as it persists in carrying out the aesthetic education of lifestyle and combines aesthetic education with other science and culture education, it will certainly be able to guide college students to step out of aesthetic misunderstandings and grow into socialist modernization High-quality talent.

\section{References}

[1] Wang Yu, Discussion on the Problems and Countermeasures in Contemporary College Students' Ideological and Political Education [J]. Chinese Market, 2016, (47): 118-119.

[2] Zhang Tianbao, Fan Xiaodong. Contemporary vocational college students sense of gratitude education lack of status, causes and countermeasures [J]. Health Vocational Education, 2015, (23): 21-23.

[3] Li Yafang. Contemporary college students lack of integrity and education strategies [J]. Journal of Zunyi Normal College, 2015, (2): 139-141,147.

[4] Duan Yuanjun. Contemporary college students ideological and political education lack of humanistic concern and analysis [J]. Journal of Hebei Youth Administrative Cadres College, 2014, (4): 21-24.

[5] Li Yan. Contemporary college students ideological and political education lack of humanistic concern and countermeasures [J] Talent, 2014, (5): 300,304.

[6] LIU Bin, ZHAO Xue. Physical Education Model of Contemporary College Students - Lack of Vocational Education and Countermeasures [J]. Chinese Talents, 2013, (6): 42-43. 